\title{
Cycloadditions of anionic N-heterocyclic carbenes of sydnone imines
}

\author{
Freese, Tyll
}

2019-05-02

Freese , T , Nieger , M , Namyslo , J C \& Schmidt , A 2019 , ' Cycloadditions of anionic $\mathrm{N}$-heterocyclic carbenes of sydnone imines ' , Tetrahedron Letters , vol. 60 , no. 18 , pp. 1272-1276 . https://doi.org/10.1016/j.tetlet.2019.04.006

http://hdl.handle.net/10138/329576

https://doi.org/10.1016/j.tetlet.2019.04.006

cc_by_nc_nd

acceptedVersion

Downloaded from Helda, University of Helsinki institutional repository.

This is an electronic reprint of the original article.

This reprint may differ from the original in pagination and typographic detail.

Please cite the original version. 


\section{Graphical Abstract}

\section{Cycloadditions of anionic $N$-heterocyclic}

carbenes of sydnone imines.

Tyll Freese, ${ }^{\mathrm{a}}$ Martin Nieger, ${ }^{\mathrm{b}}$ Jan C. Namyslo, ${ }^{\mathrm{a}}$ and Andreas Schmidt ${ }^{\mathrm{a} *}$

${ }^{a}$ Clausthal University of Technology, Institute of Organic Chemistry, D-38678 Clausthal-Zellerfeld, Germany.

${ }^{b}$ University of Helsinki, Department of Chemistry, P.O. Box 55, FIN-00014 Helsinki, Finland.

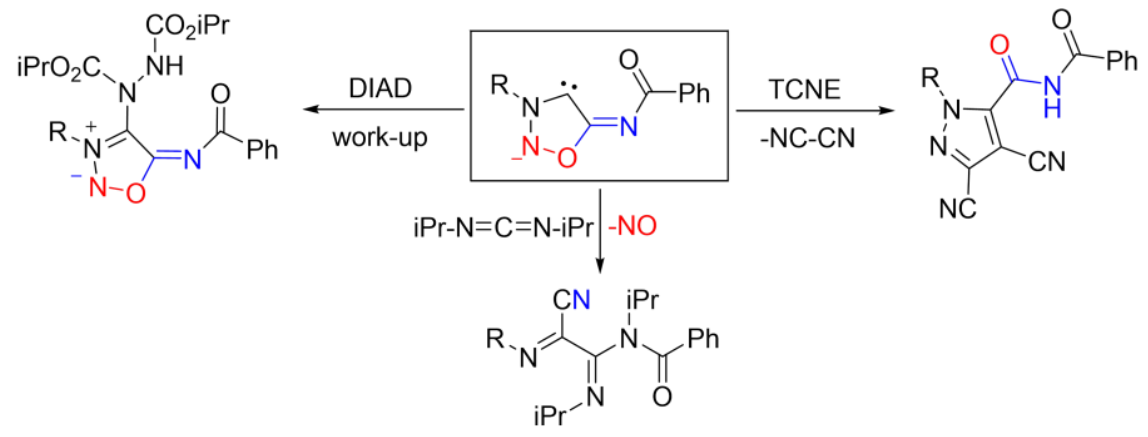


Tetrahedron Letters

journal homepage: www.elsevier.com

\title{
Cycloadditions of anionic $N$-heterocyclic carbenes of sydnone imines
}

\author{
Tyll Freese, ${ }^{\mathrm{a}}$ Martin Nieger, ${ }^{\mathrm{b}}$ Jan C. Namyslo, ${ }^{\mathrm{a}}$ and Andreas Schmidt ${ }^{\mathrm{a} *}$ \\ ${ }^{a}$ Clausthal University of Technology, Institute of Organic Chemistry, Leibnizstrasse 6, D-38678 Clausthal-Zellerfeld, Germany. Phone: +49-5323-72-3861; \\ Email: schmidt@ioc.tu-clausthal.de \\ ${ }^{b}$ University of Helsinki, Department of Chemistry, P.O. Box 55, FIN-00014 Helsinki, Finland.
}

\section{ARTICLE INFO}

\section{ABSTRACT}

\section{Article history:}

Received

Received in revised form

Accepted

Available online

\section{Keywords:}

Mesoionic compounds

1,3-Dipoles

Tautomerism

Pyrazole

Bisiminonitrile
Sydnone imines were deprotonated with lithium bis(trimethylsilyl)amide at the $\mathrm{C} 4$ position to give the corresponding sydnone imine anions as lithium adducts. These can be represented as lithium stabilized anionic $N$-heterocyclic carbenes. Treatment with diisopropyl azodicarboxylate (DIAD) gave the corresponding $\mathrm{C} 4$ adducts, i.e. 4-hydrazinyl-sydnone imines, which form tautomers in solution. Reductive 1,3-dipolar cycloadditions of the sydnone imine anions with tetracyanoethylene (TCNE) resulted in the formation of pyrazoles, the mechanism of formation of which differs from known reactions. Reaction of the anion derived from the 2-methoxyphenyl sydnone imine with $N, N$-diisopropylcarbodiimide gave a ring-cleaved bisiminonitrile. Structure elucidations were accomplished by NMR spectroscopy and by four single crystal X-ray analyses.

2019 Elsevier Ltd. All rights reserved.

\section{Introduction}

1,2,3-Oxadiazolium-5-olates ${ }^{1}$ constitute the parent compounds of the sydnone family, the first member of which was unknowingly synthesized in $1935 .^{2}$ Sydnone imines ${ }^{3}$ as well as sydnone methides ${ }^{4}$ are derivatives of sydnones with exocyclic nitrogen and carbon substituents instead of oxygen, respectively (Scheme 1). Considerable interest has been focused on sydnones as starting materials in synthetic organic chemistry ${ }^{1}$ (vide infra), potential drugs (antibiotics, ${ }^{5}$ anti-cancer compounds, ${ }^{6}$ antidiabetics, ${ }^{7}$ antifungal, ${ }^{8}$ anti-inflammatory, ${ }^{9}$ anti-HIV agents ${ }^{10}$ ) and technical applications such as molecular imaging. ${ }^{11}$ In comparison to sydnones, much less is known about sydnone imines. Concerning the biological activity, the NO donor and vasodilating drug Molsidomine (Corvasal, Corvaton, Molsidain, Molsidolat), however, is a prominent and widely applied sydnone imine to which interest has been directed with respect to antiarrhythmogenic, ${ }^{12}$ anxiolytic, ${ }^{13}$ cardioprotective, ${ }^{14}$ and cerebral vasospasm-associated activities. ${ }^{15}$ Sydnone methides are extremely rare and, to the best of our knowledge, no information is available concerning the biological activities. ${ }^{16}$

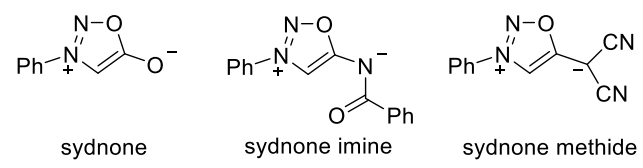

Scheme 1. The sydnone family of compounds

All sydnone derivatives belong to the class of mesomeric betaines. These can exclusively be represented by canonical forms in which the positive and negative charges are delocalized within a common $\pi$-electron system. According to a recent classification by Ramsden and Oziminski five distinct classes of mesomeric betaines can be distinguished by matrix-connectivity analyses. ${ }^{17}$ Sydnones $(Z=O)$ as well as sydnone imines $(Z=N R)$ and sydnone methides $\left(\mathrm{Z}=\mathrm{CR}_{2}\right)$ belong to the class of conjugated mesomeric betaines (CMB). They can be represented by a number of canonical formulae some of which are shown in Scheme 2. In sydnone imines and sydnone methides, the delocalization of the negative charges is extended into the exocyclic substituent.

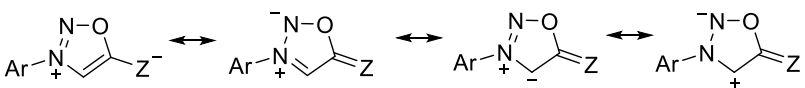

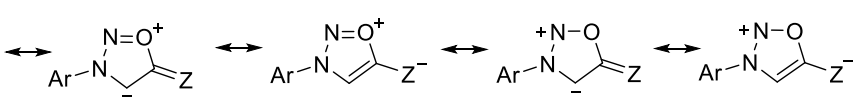

$$
\begin{aligned}
& \begin{array}{l}
\begin{array}{l}
\text { sites of negative charges } \\
\text { sites of positive charges } \\
\text { sites of positive and negative charges } \\
\text { in the dipolar resonance forms }
\end{array} \\
\text { nar }
\end{array}
\end{aligned}
$$

Scheme 2. Some canonical formulae of sydnone derivatives.

Characteristic of the class of conjugated mesomeric betaines common sites for either charge exist in the canonical formulae. ${ }^{18}$ Most of the resonance forms suggest exocyclic double bonds, i.e. carbonyl groups $(Z=O)$, imine groups $(Z=N R)$, or exocyclic alkene groups $\left(Z=\mathrm{CR}_{2}\right)$. For sydnones, these are in accordance with the results of single crystal X-ray analyses as well as 
vibrational spectroscopic investigations which hint at a bond order of $1.99 .{ }^{19}$ In sydnone imines, the exocyclic $\mathrm{C}-\mathrm{N}$ bond is usually slightly longer than the $\mathrm{C}=\mathrm{N}$ double bond of imines. ${ }^{20}$ The characteristic dipole type of conjugated mesomeric betaines can also be dissected from the mesomeric structures of sydnone derivatives (Scheme 3). Indeed, sydnones $\mathbf{1}$ are known to be versatile masked 1,3-dipoles in cycloadditions. ${ }^{18}$ Thus, numerous acetylenes give pyrazoles $\mathbf{2}^{21}$ and regioselectivity studies have been performed. ${ }^{22}$ Alkenes mainly possessing electronwithdrawing groups give 4,5-dihydro- $1 H$-pyrazoles $\mathbf{3 .}^{23}$ Cycloadditions of sydnones with heterocumulenes are rare. A photochemical synthesis of 1,2,4-triazol-3-one $\mathbf{4}$ with phenylisocyanate $\left(\mathrm{R}^{\prime}=\mathrm{Ph}\right)$ was described, and carbon disulfide and carbon dioxide reacted similarly. ${ }^{24}$ It was furthermore reported that (2,2-dimethylpropylidyne)phosphane gave 3-(tert-butyl)-1methyl-1H-1,2,4-diazaphosphole $5\left(\mathrm{R}^{\prime}=\mathrm{Me}\right){ }^{25}$ The valence tautomer 6, which was originally postulated as a structure of sydnones in $1935^{2}$ and as an intermediate of the aforementioned photochemical reactions, ${ }^{24}$ was generated by a matrix photolysis. ${ }^{26}$ Cycloadditions of sydnone imines $(Z=N R)$ are very rare. Very recently they have attracted attention as masked 1,3-dipoles in cycloreactions with acetylenes. ${ }^{11,27}$ Thus, bioorthogonal click and release reactions of sydnone imines with cycloalkynes have been described $^{28}$ and patented. ${ }^{29}$

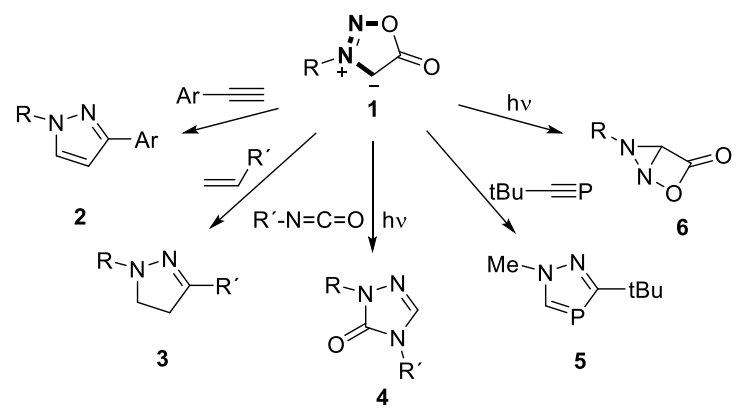

Scheme 3. Reactions involving the masked 1,3-dipole of sydnones.

Upon deprotonation with suitable bases, anions of sydnones ${ }^{19,30}$ as well as of sydnone imines ${ }^{31}$ are formed which can be represented as anionic $N$-heterocyclic carbenes (Scheme 4). ${ }^{19,20}$ These undergo numerous trapping reactions $\left(\mathrm{S},{ }^{32,33} \mathrm{~B},{ }^{33} \mathrm{Se},{ }^{34} \mathrm{Au},{ }^{34}\right.$ $\left.\mathrm{Pd}^{34}\right)$. Nucleophilic ring transformations have also been reported. ${ }^{35}$ Thus, sydnone and sydnone imine anions combine the features of $N$-heterocyclic carbenes due to their $\sigma$ lone pair and of conjugated mesomeric betaines due to their characteristic $\pi$-architecture. Consequently, the highest occupied molecular orbitals (HOMO) which are $\pi$-orbitals, display large atomic orbital coefficients on $\mathrm{C} 4$ which seem to be a common feature of the most of anionic $\mathrm{N}$ heterocyclic carbenes derived from mesoionic compounds. ${ }^{36}$ Some results have been summarized in review articles. ${ }^{37}$

In continuation of our studies directed toward the chemistry of mesomeric betaines and their potential conversions into $\mathrm{N}$ heterocyclic carbenes, and as part of our studies directed toward the chemical and physical consequences of different types of conjugation, we describe herein reactions of sydnone imines which take advantage of the combination of $\sigma$ - and $\pi$ characteristics of their anions.

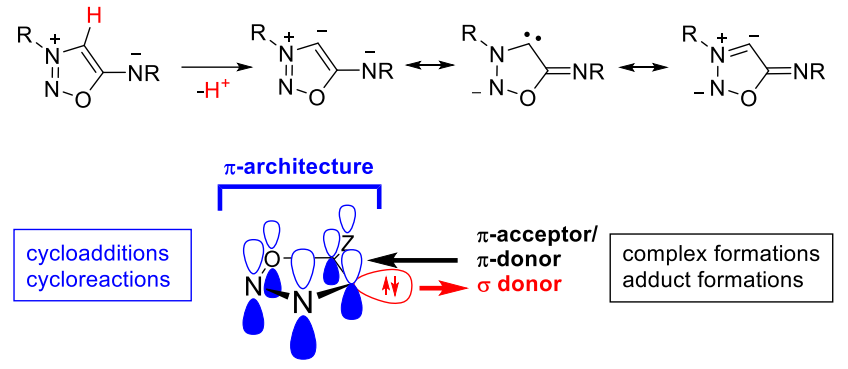

Scheme 4. Sydnone imine anions combine features of anionic $N$ heterocyclic carbenes and $\pi$-electron-rich heteroaromatics.

\section{Results and Discussion}

Deprotonation of the sydnone imines $\mathbf{7 a - c}$ by lithium bis(trimethylsilyl)amide at rt gave the sydnone imine anions 8a-c which were subsequently treated with diisoproyl azodicarboxylate (DIAD) to give the adducts 9a-c as a mixture of tautomers in moderate yields (Scheme 5). Under these conditions, the sydnone imine carbenes reacted as $C$-nucleophiles. To the best of our knowledge, no $\mathrm{C}-\mathrm{N}$ bond formation starting from sydnone imines has been described so far, as the structure of 4-hydrazinosydnone, initially postulated, proved to be incorrect. ${ }^{38}$

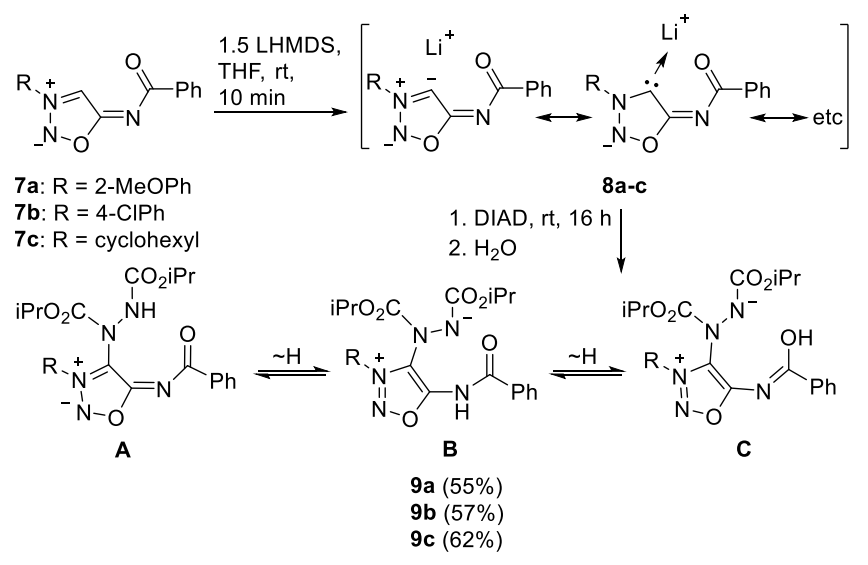

Scheme 5. Reaction of sydnone imines 7a-c with diisopropyl azodicarboxylate after deprotonation.

The structures of the tautomers of $\mathbf{9 a - c}$ were confirmed by 2DHMBC NMR measurements. The major tautomers are 9a-cA. At room temperature the ${ }^{1} \mathrm{H}$ NMR spectra display broad signals of the protons of the substituents $(\mathrm{R})$, the protons of the diisopropyl groups and more than one broad signal for the proton involved in tautomerism. For further investigations we performed NMR experiments in the temperature range of $25{ }^{\circ} \mathrm{C}$ to $80{ }^{\circ} \mathrm{C}$ in anhydrous deuterated DMSO. With increasing temperature just one signal of the proton involved in tautomerism can be observed, while the aforementioned broad signals become more and more defined, resulting in sharp multiplets at $80{ }^{\circ} \mathrm{C}$. Upon cooling to 25 ${ }^{\circ} \mathrm{C}$, the signal broadening proved to be reproducible. Suitable crystals for single crystal X-ray analysis were obtained by cooling a saturated solution of the compound in a DMSO-water mixture (10:1). The molecular drawing (Fig. 1) shows a strong hydrogen bond between $\mathrm{N} 23-\mathrm{H}$ and the $\mathrm{O} 7$ oxygen atom $(\mathrm{N} 23-\mathrm{H} . \ldots . \mathrm{O} 7=$ 206(1) pm), indicating a possible tautomeric structure 9aC as 
shown in Scheme 3. In solutions with free bond rotations the tautomeric structures 9a-cC are also highly probable. The molecule crystallized monoclinic. Results of the X-ray analysis show an almost planar alignment between the oxadiazole ring and the exocyclic imine group, as a torsion angle of $6^{\circ}$ was found. The 2-methoxyphenyl ring is twisted by $83^{\circ}$ which cause an interrupted $\pi$-conjugation. Hydrogen bonding (N23-H..... and the $\mathrm{N}-\mathrm{CO}_{2}{ }^{\mathrm{i}} \mathrm{Pr}$ groups are twisted by $85^{\circ}$ towards each other.

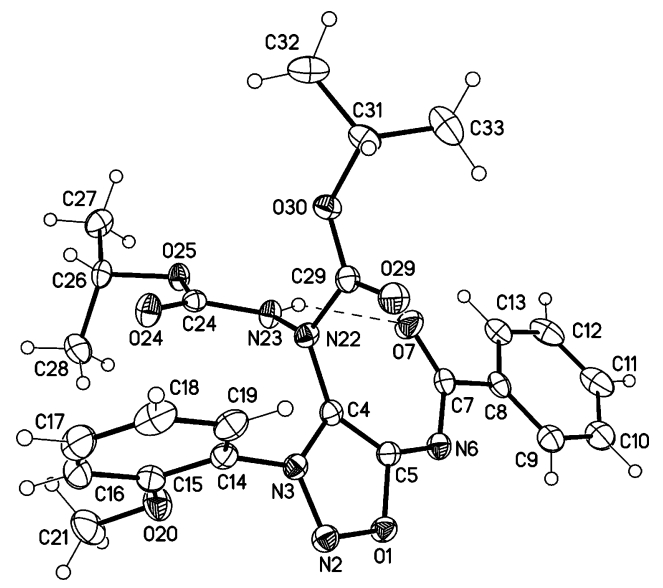

Figure 1. Molecular drawing of C4-substituted sydnone imine 9aA (displacement parameters are drawn at the $50 \%$ probability level). Selected bond lengths [pm] (crystallographic numbering): O1-N2: 137.43(12), N2-N3: 129.98(13), N3-C4: 136.08(14), C4C5: 140.40(15), O1-C5: 138.68(13), C5-N6: 131.01(15), N6-C7: 136.48(14), C7-O7: 123.17(14), C4-N22: 139.34(14), N22-N23: 138.58(12), N23-H23-O7: 206(1) pm.

Reductive 1,3-dipolar cycloadditions of the sydnone imine anions 8a-c require a nucleophilic $\mathrm{C} 4$ position plus a participating $\pi$-conjugative system to intercept the resulting terminal anion. We performed these reactions starting from freshly prepared 4sydnone imine anions 8a-c and tetracyanoethylene (TCNE) in anhydrous THF at room temperature and obtained the pyrazoles 10a-c in good yields (Scheme 6). No reaction of the sydnone imines 7a-c and TCNE in the absence of base can be observed. Even at elevated temperatures in anhydrous THF at $65{ }^{\circ} \mathrm{C}$ or in anhydrous toluene at reflux and prolonged reaction times of $6 \mathrm{~h}$ no cycloaddition $(\mathbf{G})$ or cycloreaction products can be found starting from 7a-c. We propose the following mechanism: nucleophilic attack at the $\mathrm{C} 4$ position of $\mathbf{8 a - c}$ gives the terminal anions $\mathbf{D}$ which induce a ring transformation by attack at N2 to give intermediate $\mathbf{E}$. Formation of cyanogen from $\mathbf{E}$ and $\mathbf{F}$ results in the formation of the heteroaromatic pyrazole, possessing an $N$-carbonyl benzamide substituent, under charge neutralization.

Structure determination was accomplished by X-ray analysis from single crystals of 10a and 10c (Figs. 2 and 3). Suitable single crystals were obtained by slow evaporation of a saturated solution from a chloroform-hexane mixture, respectively. Although both single crystals show closely related bond lengths and bond angles, the crystallization adopts different Bravais lattices and space groups (monoclinic, $\mathrm{P} 2_{1} / \mathrm{c}$ for $\mathbf{1 0 a}$ and orthorhombic, $\mathrm{P} 2{ }_{1} 2_{1} 2_{1}$ for 10c). Furthermore, varying torsion angles are observed between the pyrazole and the carbonylbenzamide fragments $\left(46^{\circ}\right.$ for $\mathbf{1 0 a}$, $36^{\circ}$ for 10c), as well as the pyrazole ring and the N1-nitrogen substituents $\left(49^{\circ}\right.$ for $\mathbf{1 0 a}, 74^{\circ}$ for $\left.\mathbf{1 0 c}\right)$

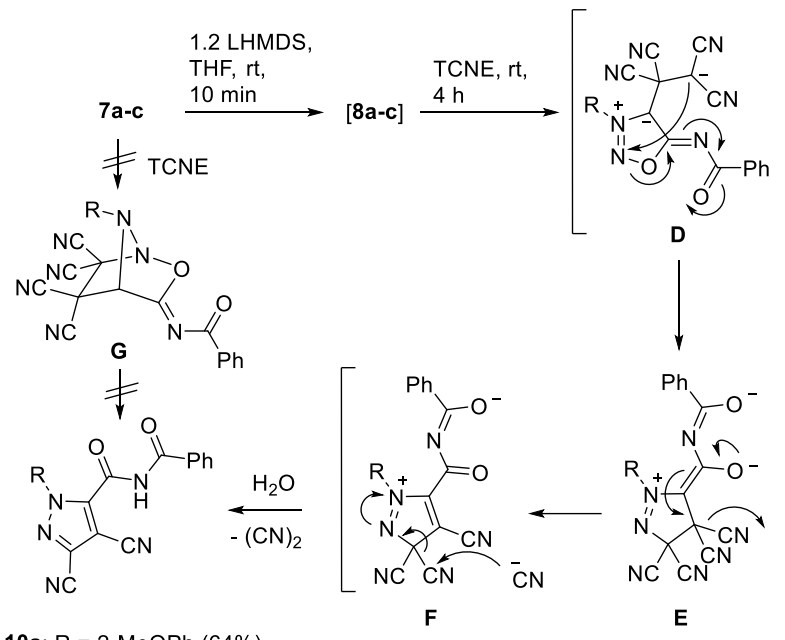

10a: $\mathrm{R}=2-\mathrm{MeOPh}(64 \%)$

10b: $\mathrm{R}=4-\mathrm{CIPh}(58 \%)$

10c: $R=$ cyclohexyl $(56 \%)$

Scheme 6. Reaction of sydnone imines 7a-c with tetracyanoethylene via their anions 8a-c

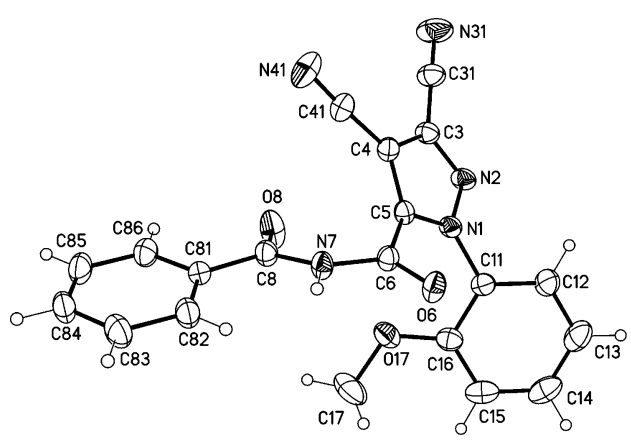

Figure 2. Molecular drawing of pyrazole 10a (displacement parameters are drawn at the $30 \%$ probability level). Selected bond lengths [pm] (crystallographic numbering): N1-N2: 134.79(13), N2-C3: 132.58(15), C3-C4: 140.73(16), C4-C5: 137.93(16), N1C5: 135.65(13), C5-C6: 149.23(15), C6-O6: 121.24(13), C6-N7: 136.84(14), N7-C8: 139.59(15), C8-O8: 120.75(15), C3-C31: 143.07(17), C31-N31: 112.96(18), C4-C41: 142.28(16), C41N41: 113.74(17) pm.

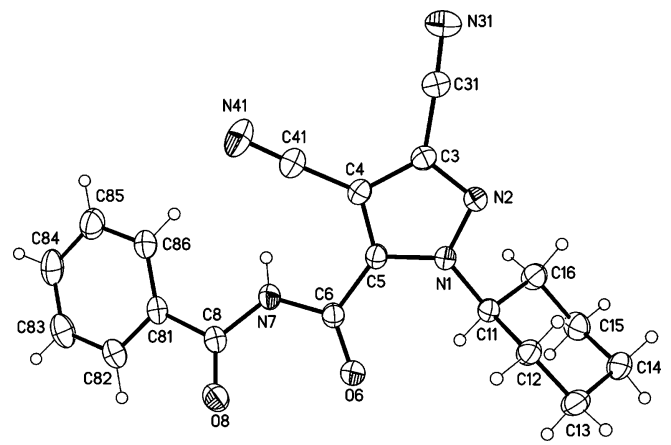

Figure 3. Molecular drawing of pyrazole 10c (displacement parameters are drawn at the $30 \%$ probability level). Selected bond lengths [pm] (crystallographic numbering): N1-N2: 134.3(2), N2C3: 132.8(2), C3-C4: 139.9(3), C4-C5: 138.7(3), N1-C5: 135.7(2), C5-C6: 148.6(2), C6-O6: 120.4(2), C6-N7: 139.0(2), N7-C8: 139.4(2), C8-O8: 121.0(3), C3-C31: 143.3(3), C31-N31: 113.9(3), C4-C41: 142.4(3), C41-N41: 113.7(3) pm. 
In contrast to the aforementioned literature-known cycloreactions of sydnone imines with alkynes by Audisio, Taran and co-workers, which proceeded by extrusion of $\mathrm{CO}_{2}$ and the former exocyclic NR group of the sydnone imine as $\mathrm{RNH}_{2}$, the reactions described here proceed via the formation of a thermodynamically stable fragment $R^{3}-R^{3}\left(R^{3}=C N\right)$ from the dipolarophile (Scheme 7). All other atoms of the starting materials remain in the final products.

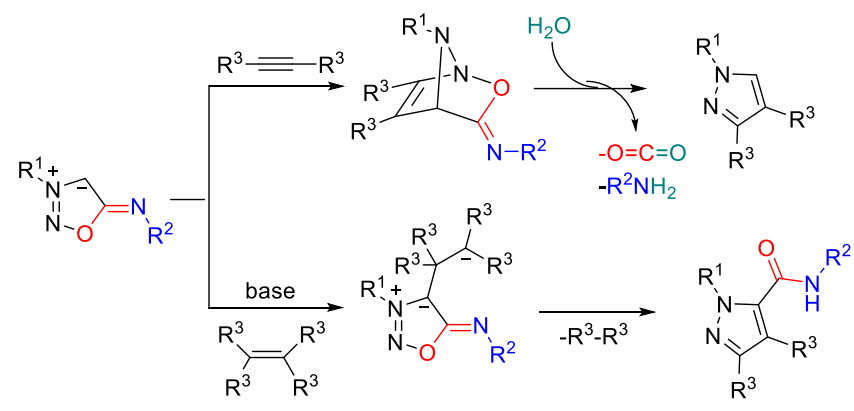

Scheme 7. Comparison: two types of pyrazole formation.

Next, we tried reactions of the sydnone imine anions 8a-c with $\mathrm{N}, \mathrm{N}$-diisopropylcarbodiimide. Indeed, the 2-methoxyphenyl substituted sydnone imine underwent a reaction to give a new class of bisiminonitriles with an intense yellow color. However, the yield is low and the derivatives $\mathbf{7 b}, \mathbf{c}$ did not react under analogous reaction conditions. We postulate the following mechanism: initial attack at the $\mathrm{C} 4$ position of 8 a gives a terminal anion which attacks the benzoyl group of the former sydnone imine. This results in the formation of the product 11a and the instable ${ }^{39}$ nitroxyl anion (Scheme 8).

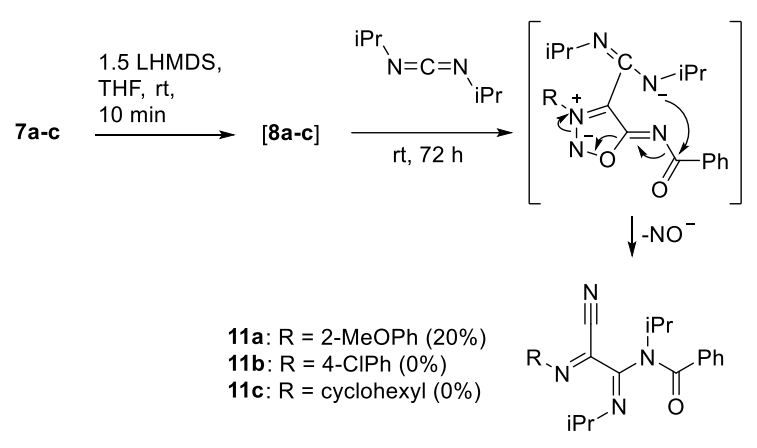

Scheme 8. Reaction of sydnone imines 7a-c with DIC.

The structure of 11a was confirmed by single crystal X-ray analysis (Fig. 4). Single crystals were obtained by slow evaporation from chloroform. Interestingly, the two imines differ in their stereoisomerism. The N1-C2 imine function shows the $E$ isomer and the C3-N31 imine displays Z-isomerism.

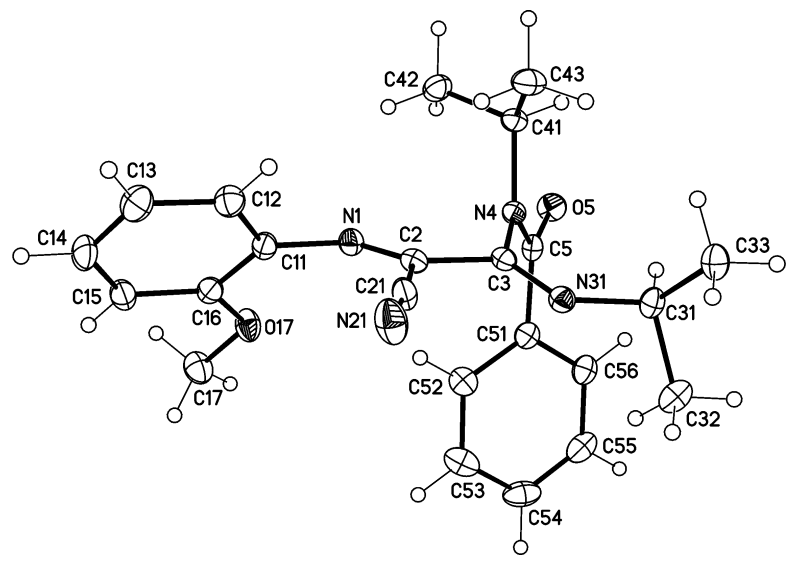

Figure 4. Molecular drawing of bisiminonitrile 11a (displacement parameters are drawn at the 50\% probability level). Selected bond lengths [pm] (crystallographic numbering): N1-C2: 127.19(14), C2-C3: 149.52(15), C3-N4: 143.29(13), N4-C5: 137.57(14), C5-O5: 122.71(13), C3-N31: 126.66(14), C2-C21: 146.49(15), C21-N21: 114.51(15) pm.

\section{Conclusion}

Sydnone imine anions combine the features of anionic $\mathrm{N}$ heterocyclic carbenes and of mesoionic compounds. They undergo trapping reactions in which they act as $C$-nucleophiles toward DIAD. Upon treatment with TCNE, the initial nucleophilic attack results in the formation of a terminal anion which induces a cycloreaction with the formation of pyrazoles.

\section{Acknowledgement}

The Deutsche Forschungsgemeinschaft DFG is gratefully acknowledged for the funding.

\section{References}

1. (a) D. L. Browne, J. P. Harrity, Tetrahedron 2010, 66, 553 - 568 (b) T. L. Gilchrist, In Science of Synthesis; R. C. Storr, T. L. Gilchrist, Ed.; Thieme Verlag: Stuttgart, Germany, 2004, Vol. 13, pp. 109 - 125. (c) R. Chandrasekhar, M. J. Nanjan, Mini-Rev. Med. Chem. 2012, 12, 1359 - 1365. (d) C. Wu, Y. Fang, R. C. Larock, F. Shi, Org. Lett. 2010, 12, 2234 - 2237. (e) S. K. Bhosalea, S. R. Deshpandeb, R. D. Waghc, J. Chem. Pharm. Res. 2015, 7, $1333-$ 1343. (f) S. T. Asundaria, C. Pannecouque, E. de Clercq, K. C. Patel, Pharm. Chem. J. 2014, 48, 260 - 268. (g) J. M. Lopchuk, Topics Heterocycl. Chem. 2012, 29, $381-414$.

2. J. C. Earl, A. W. Mackney, J. Chem. Soc. 1935, 899.

3. V. G. Yashunskii, L. E. Kholodov, Russ. Chem. Rev. 1980, 49, 28 -45 .

4. S. Araki, J. Mizuya, Y. Butsugan, J. Chem. Soc., Perkin Trans 1, 1985, 11, 2439-2441.

5. N. O. Corneli, F. Albota, C. C. Dragomirescu, M. D. Stanescu, Farmacia 2018, 66, $658-662$.

6. (a) A. W. Brown, T. Holmes, M. Fisher, G. M. Tozer, J. P. A. Harrity, C. Kanthou, ChemMedChem 2018, 13, 2618 - 2626. (b) S. K. Bhosale, S. R. Deshpande, R. D. Wagh, Pakistan J. Pharm. Sci. 2017, 30, 513 - 520. (c) L. F. Galuppo, F. A. dos Reis Livero, G. G. Martins, C. C. Cardoso, O. C. Beltrame, L. M. Bacaro Klassen, A. V. dos Santos Canuto, A. Echevarria, J. E. Queiroz Telles, G. Klassen, A. Acco, Basic Clin. Pharm. Tox. 2016, 119, $41-50$.

7. G. Tegginamath, R. R. Kamble, P. P. Kattimani, S. B. Margankop, Arab. J. Chem. 2016, 9, S306 - S312.

8. (a) N. D. Thanh, H. T. Duc, V. T. Duyen, P. M. Tuong, N. V. Quoc, Chem. Central J. 2015, 9, 60. (DOI: 10.1186/s13065-015-0138-8). 
(b) V. K. Akbari, N. J. Chothani, Y. M. Patel, K. C. Patel, Ind. J. Chem. Sect. B, 2015, 54, $93-102$.

9. Y. M. Patel, K. C. Patel, J. Saud. Chem. Soc. 2015, 19, 193 - 199.

10. S. T. Asundaria, C. Pannecouque, E. De Clercq, K. C. Patel, Pharm. Chem. J. 2014, 48, $260-268$.

11. (a) E. Decuypere, M. Riomet, A. Sallustrau, S. Bregant, R. Thai, G. Pieters, G. Clavier, D. Audisio, F. Taran, Chem. Commun. 2018, 54, 10758 - 10761. (b) L. C.-C. Lee, H. M.-H. Cheung, H.-W. Liu, K. K.-W. Lo, Chem. Eur. J. 2018, 24, $14064-14068$.

12. Y. Shan, D. Wang, R. Li, C. Huang, J. Cardiovasc. Pharmacol., 2016, 68, $342-355$

13. T. Kalouda, N. Pitsikas, Pharm., Biochem. Behav. 2015, 138, 111 116.

14. O. M. Disli, E. Sarihan, M. C. Colak, N. Vardi, A. Polat, J. Yagmur, B. Tamtekin, H. Parlakpinar, Eur. Surg. Res., 2013, 51, 79 - 90.

15. A. Ehlert, C. Schmidt, PCT Int. Appl. 2012, WO 2012069620 A1 20120531.

16. J. Mizuya, Y. Butsugan, S. Araki, Chem. Lett. 1984, 1045 - 1046.

17. (a) C. A. Ramsden, Prog. Heterocycl. Chem. 2016, 28, 1 - 25. (b) C. A. Ramsden, Tetrahedron 2013, 69, 4146 - 4159. (c) C. A. Ramsden, W. P. Oziminski, Tetrahedron 2014, 70, 7158 - 7165. (d) W. P. Oziminski, C. A. Ramsden, Tetrahedron 2015, 71, 7191 -7198 .

18. W. D. Ollis, S. P. Stanforth, C. A. Ramsden, Tetrahedron 1985, 41, $2239-2329$.

19. S. Wiechmann, T. Freese, M. H. H. Drafz, E. G. Hübner, J. C. Namyslo, M. Nieger, A. Schmidt, Chem. Commun. 2014, 50, 11822 $-11824$.

20. T. Freese, A.-L. Lücke, J. C. Namyslo, M. Nieger, A. Schmidt, Eur. J. Org. Chem. 2018, $1646-1654$.

21. (a) C. Favre, F. Friscourt, Org. Lett. 2018, 20, 4213-4217. (b) A. W. Brown, J. P. A. Harrity, Tetrahedron 2017, 73, 3160 - 3172. (c) J. Comas-Barcelo, R. S. Foster, B. Fiser, E. Gomez-Bengoa, J. P. A. Harrity, Chem. Eur. J. 2015, 21, 3257 - 3263. (d) S. Kolodych, E. Rasolofonjatovo, M. Chaumontet, M.-C. Nevers, C. Creminon, F. Taran, Angew. Chem. Int. Ed. 2013, 52, 12056 - 12060. (e) K. C. Nicolaou, B. A. Pratt, S. Arseniyadis, M. Wartmann, A. O'Brate, P. Giannakakou, ChemMedChem 2006, 1, 41 - 44. (f) D. L. Browne, J. B. Taylor, A. Plant, J. P. A. Harrity, J. Org. Chem. 2010, 75, 984 - 987. (g) R. Huisgen, H. Gotthardt, R. Grashey, Chem. Ber. 1968, 101, $536-551$.

22. R. S. Foster, H. Jakobi, J. P. A. Harrity, Tetrahedron Lett. 2011, 52 , $1506-1508$.

23. (a) L. Zhang, X. Zhang, Z. Yao, S. Jiang, J. Deng, B. Li, Z. Yu, J. Am. Chem. Soc. 2018, 140, 7390 - 7394. (b) A. M. GonzalezNogal, M. Calle, P. Cuadrado, R. Valero, Tetrahedron 2007, 63, 224 - 231. (c) K. Butković, Ž. Marinić, K. Molčanov, B. KojićProdić, M. Šindler-Kulyk, Beilstein J. Org. Chem. 2011, 7, 1663 1670. (d) L. K. Vagina, V. N. Chistokletov, A. A. Petrov, Zhur. Organich. Khim. 1965, 1, 1700 - 1703. (e) H. Gotthardt, F. Reiter, Chem. Ber. 1979, 112, $1206-1225$.

24. K. H. Pfoertner, J. Foricher, Helv. Chim. Acta 1980, 63, 653-657.

25. W. Roesch, H. Richter, M. Regitz, Chem. Ber. 1987, 120, $1809-$ 1813.

26. R. N. Veedu, D. Kvaskoff, C. Wentrup, Aust. J. Chem. 2014, 67, $457-468$

27. (a) H. H. Tao, F. Liu, R. Zeng, Z. Shao, L. Zou, Y. Cao, J. M Murphy, K. N. Houk, Y. Liang, Chem. Commun. 2018, 54, $5082-$ 5085. (b) C. Favre, L. de Cremoux, J. Badaut, F. Friscourt, J. Org. Chem. 2018, 83, 2058 - 2066. (c) E. Decuypere, L. Plougastel, D. Audisio, F. Taran, Chem. Commun. 2017, 53, 11515 - 11527. (e) A. W. Brown, J. P. A. Harrity, Tetrahedron 2017, 73, 3160-3172. (f) A. W. Brown, J. Comas-Barcelo, J. P. A. Harrity, Chem. Eur. J. 2017, 23, 5228 - 5231 .

28. (a) S. Bernard, D. Audisio, M. Riomet, S. Bregant, A. Sallustrau, L. Plougastel, E. Decuypere, S. Gabillet, R. A. Kumar, J. Elyian, M. N. Trinh, O. Koniev, A. Wagner, S. Kolodych, F. Taran, Angew. Chem., Int. Ed. 2017, 56, 15612 - 15616. (b) M. Riomet, E. Decuypere, K. Porte, S. Bernard, L. Plougastel, S. Kolodych, D. Audisio, F. Taran, Chem. Eur. J. 2018, 24, 8535 - 8541.

29. (a) F. Taran, A. Wagner, S. Kolodych, O. Koniev, PCT Int. Appl. 2015, WO 2015193455. (b) F. Taran, A. Wagner, S. Kolodych, O. Koniev, Eur. Pat. Appl. 2015, EP 2957559

30. (a) A.-L. Lücke, S. Wiechmann, T. Freese, M. Nieger, T. Foeldes, I. Pápai, M. Gjikaj, A. Adam, A. Schmidt, Tetrahedron 2018, 74 2092 - 2099. (b) T. Wezeman, J. Comas-Barcelo, M. Nieger, J. P. A. Harrity, S. Bräse, Org. Biomol. Chem. 2017, 15, 1575 - 1579. (c) N. N. Chitiyo, A. Y. Dossa, C. M. Jackson, L. Sun, K. Turnbull,
Org. Prep. Proc. Int. 2016, 48, 405 - 412. (d) M. G. Ezernitskaya, B. V. Lokshin, E. I. Kazimirchuk, V. N. Khandozhko, V. N. Kalinin, Mikrochim. Acta, Supplement 1997, 14, 381 - 382. (e) V. N. Kalinin, P. M. Se, J. Organomet. Chem. 1988, 352, C34 - C36. (f) T. Fuchigami, C. S. Chen, T. Nonaka, M. Y. Yen, H. J. Tien, Bull. Chem. Soc. Jpn. 1986, 59, 487 - 491. (g) N. Suciu, G. Mihai, Tetrahedron 1968, 24, 37 - 42. (h) C. V. Greco, M. Pesce, J. M. Franco, J. Heterocycl. Chem. 1966, 3, 391 - 392.

31. (a) I. A. Cherepanov, L. H. Kusaeva, I. A. Godovikov, V. N. Kalinin, Russ. Chem. Bull. 2009, 58, 2474 - 2477. (b) I. A. Cherepanov, N. V. Egorova, K. B. Nartinovich, V. N. Kalinin, Dokl. Akad. Nauk 2000, 374, 64 - 67. (c) I. A. Cherepanov, V. N. Kalinin, Mendeleev Commun. 2000, 5, 181 - 182. (d) I. A. Cherepanov, A. S. Samarskaya, R. G. Nosov, I. A. Godovikov, Y. V. Nelyubina, V. N. Kalinin, Mendeleev Commun. 2014, 24, $386-$ 387. (e) V. N. Kalinin, S. N. Lebedev, I. A. Cherepanov, I. A. Godovikov, K. A. Lyssenko, Evamarie Hey-Hawkins, Polyhedron 2009, 28, $2411-2417$

32. (a) A. S. Samarskaya, I. A. Cherepanov, I. A. Godovikov, A. O. Dmitrienko, S. K. Moiseev, V. N. N. Kalinin, E. Hey-Hawkins, Tetrahedron 2018, 74, 2693 - 2702. (b) S. N. Lebedev, I. A. Cherepanov, V. N. Kalinin, Russ. Chem. Bull. 2002, 51, 899-900.

33. T. Freese, A. Schmidt, unpublished results.

34. T. Freese, A.-L. Lücke, C. A. S. Schmidt, M. Polamo, M. Nieger, J. C. Namyslo, A. Schmidt, Tetrahedron 2017, 73, 5350 - 5357.

35. T. Freese, A.-L. Lücke, J. C. Namyslo, M. Nieger, A. Schmidt, Eur. J. Org. Chem. 2018, $1646-1654$.

36. (a) J. Zhang, N. Pidlypnyi, M. Nieger, J. C. Namyslo, A. Schmidt, Org. Biomol. Chem. 2014, 12, 2737 - 2744. (b) N. Pidlypnyi, S. Wolf, M. Liu, K. Rissanen, M. Nieger, A. Schmidt, Tetrahedron 2014, 70, 8672 - 8680. (c) M. Liu, M. Nieger, E. Hübner, A. Schmidt, Chem. Eur. J. 2016, 5416 - 5424.

37. (a) A. Schmidt, S. Wiechmann, T. Freese, ARKIVOC 2013, $i, 424-$ 469. (b) A. Schmidt, S. Wiechmann, C. F. Otto, Adv. Heterocycl. Chem. 2016, 119, $143-172$.

38. H. Kato, M. Ohta, Chem. Commun. 1966, 15, 525a - 525a.

39. N. Kawanami, T. Ozeki, A. Yagasaki, J. Am. Chem. Soc. 2000, 122, 1239 - 1240 